\title{
Experimental and Numerical Investigation of Impact Characteristics of the E-Glass/Toughened Vinylester Composite Car Hood Panels
}

\author{
Gurpinder S. Dhaliwal $^{1} \cdot$ Golam M. Newaz $^{1}$
}

Received: 4 August 2016/Accepted: 14 October 2016/Published online: 20 October 2016

(c) Society for Experimental Mechanics, Inc 2016

\begin{abstract}
This study involves experimental and numerical investigation on the impact response of a section of typical car hood having reinforcement in its inner layer containing a common X-shaped hat section. The hood specimens were developed by utilizing E-glass/Vinylester prepreg. The effect of stiffening the inner layer's reinforcement region by placing a balsawood layer in the $\mathrm{X}$-shaped hat section was also studied. Impact test was performed by driving the impacting pendulum by using the pneumatic device at a velocity of $4.1 \mathrm{~m} / \mathrm{s}$ to evaluate the impact response of the composite hood panels having balsawood layer and of those without it. Impact test results; load-time, displacement-time, load-deflection history from experimental is presented at $200 \mathrm{~kJ}$ impact energy. Explicit finite element analysis was performed by utilizing commercially available LS-Dyna code. The computational model was developed to predict the response of both types of composite car hood panels under dynamic loading. A comparison of the experimental results i.e., deflection-time, load-time histories and kinetic energy with FEA results for both types of composite car hood panels was made. Results correlate well and form the basis for analyzing and designing such new lightweight material systems for automotive applications.
\end{abstract}

Keywords E-glass/vinyl ester - Impact test · FEM - Balsa wood

Gurpinder S. Dhaliwal

gurpinder01@gmail.com

Golam M. Newaz

gnewaz@eng.wayne.edu

1 Department of Mechanical Engineering, Wayne State University, Detroit, USA

\section{Introduction}

Composite laminates offer significant weight reduction for structural parts of automobiles. For applications in the automotive industry, weight savings and strength of structure influenced the work with respect to light weight composite materials. Sandwich construction consists of two thin stiff laminates bonded with a low density material in between. In a sandwich composite, skin will be adhesively bonded to the core for transferring the load between the components, thereby one skin acts in compression as the other skin acts under tension and the core resists the shear loads. This provides high stiffness, bending rigidity, strength-to-weight ratio and energy absorbing capability to the structure. The bond must be strong enough to resist shear and tensile stresses in the sandwich panel. The composite sandwich structures nowadays are widely used in many areas where lightweight materials in-plane and flexural stiffness are required [1]. These composite materials are being used in a number of applications within the marine, aerospace, and automotive industries because they have desirable properties, such as being lightweight, having corrosion resistance, electrical and thermal insulation. These are the added advantages of composites over steel in such applications [2]. Currently, different types of core materials, such as polymeric foam core, honeycomb core, aluminum core, etc. have been used. These cores have a different damage behavior when subject to low velocity impact [3].

Low velocity impact damage may occur during normal maintenance operations or during manufacture, service and inspection [4]. Many of these damages are the result of impact by foreign objects such as tool drops, run away debris, bird strikes and also hail [5-7]. Therefore, a number of researchers in literature have focused on the impact of 
composites structures. Among these, Vaidya et al. [8] performed experiments to study the behavior of composite sandwich plate with laminate face sheet (glass/fiber carbon) and aluminum foam core under low velocity $(5 \mathrm{~m} / \mathrm{s})$ and medium $(100 \mathrm{~m} / \mathrm{s})$ velocity impact. The vibration response of sandwich composite structure was also studied. From the impact test results, they concluded that the sandwich construction with S2-glass face sheet in conjunction with aluminum foam core was optimal for resisting low and intermediate velocity impact. The effect of manufacturing on impact damage behavior in E-glass/ polyester-PVC foam core sandwich structures has been studied by Imielinska et al. [9]. Low velocity impact response of sandwich plates was also investigated by using impact drop tower. Damage initiation and failure mechanisms were recorded by high-speed photography and related to the load-time plots. Ulven and Vaidya [10] have examined impact response of fire damaged E-glass/vinyl ester laminates and balsa wood core sandwich composites

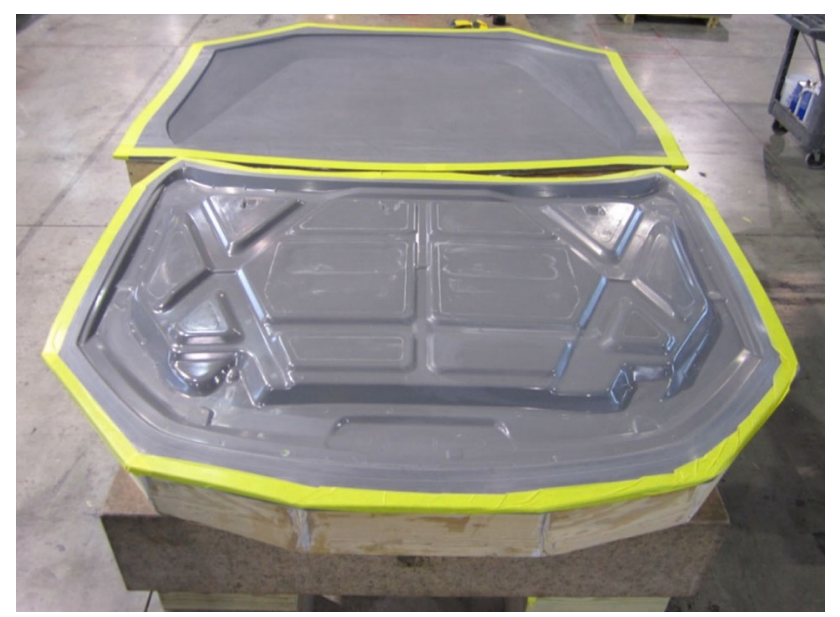

Fig. 1 Hood inner and outer panel soft tools
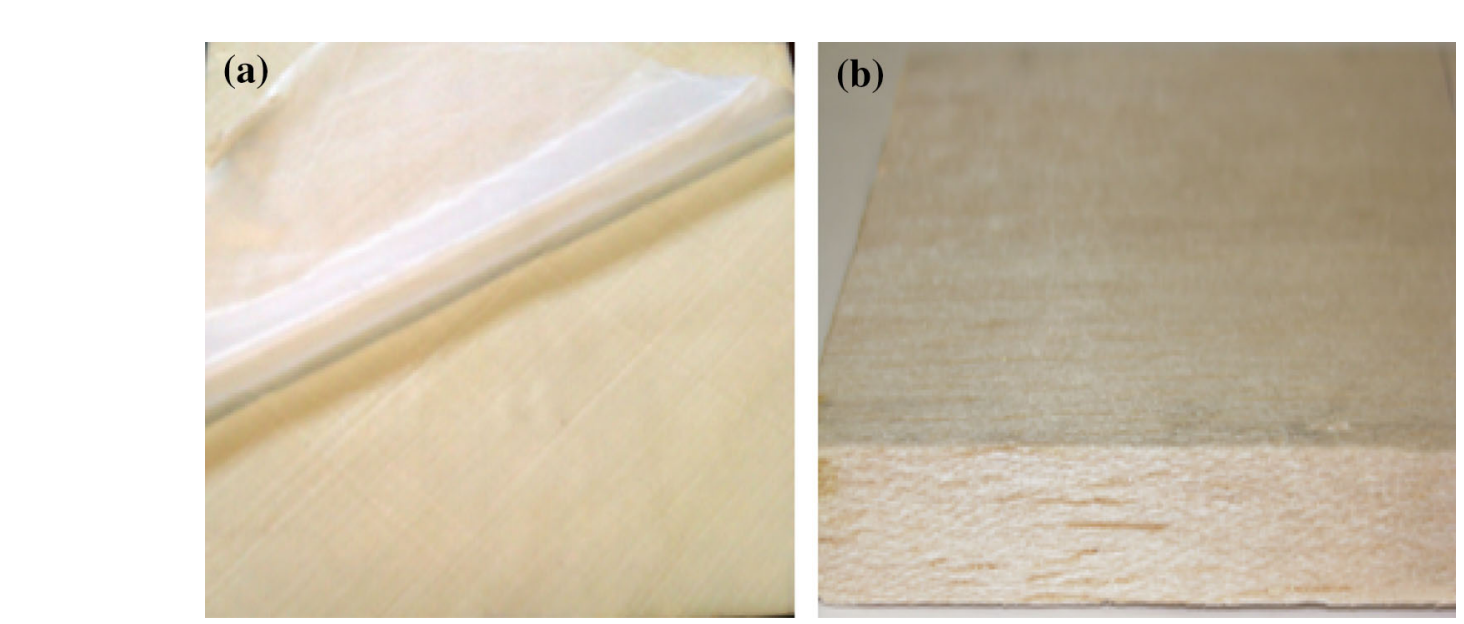

Fig. 2 Materials used to develop composite car hood panels a E-glass prepreg and b Regular balsawood with E-glass/vinyl ester face-sheets. The response of sandwich structure consisting of S2- glass/epoxy face sheets and end grain balsa core under high velocity impact has been studied experimentally and numerically by Deka and Vaidya [11]. Energy absorption and delamination from high velocity impacts were discussed and FE modeling was used to predict the damage in the sandwich composite structure. The results of FE modeling were compared with experimental data and good agreement had been obtained. Atas and Sevim [12] have experimentally investigated on the impact response of sandwich composites with cores of balsa wood and PVC foam. A number of tests under different impact energies were conducted where the results of these tests showed that the sandwich with balsa wood core absorbed energy better than panel with PVC core and were showed the damage modes are fiber fracture at upper and lower skins, delamination between adjacent layers of glass-epoxy, shear fractures of the core and face/core debonding. In addition to the single impacts, repeated impact response of the specimens was also investigated. Wang et al. [13] investigated low velocity impact characteristics and residual tensile strength of carbon fiber composite lattice core sandwich structure, experimentally and numerically. Kim and Jun [14] have investigated the effect of the lay-up of the facing and density of the honey comb core on the impact damage area of the facing. This investigation was shown that a small relative orientation results in a smaller delamination area than for a laminate with exactly the same lay-up.

Many authors have presented an experimental investigation on the damage response of composite laminates [15-21]. Strait et al. [22] have performed impact test on composite laminate with varies stacking sequence. It is found that the stacking sequence has a big effect on the impact resistance. The damage resistance and residual strength for composite laminates under low velocity impact 


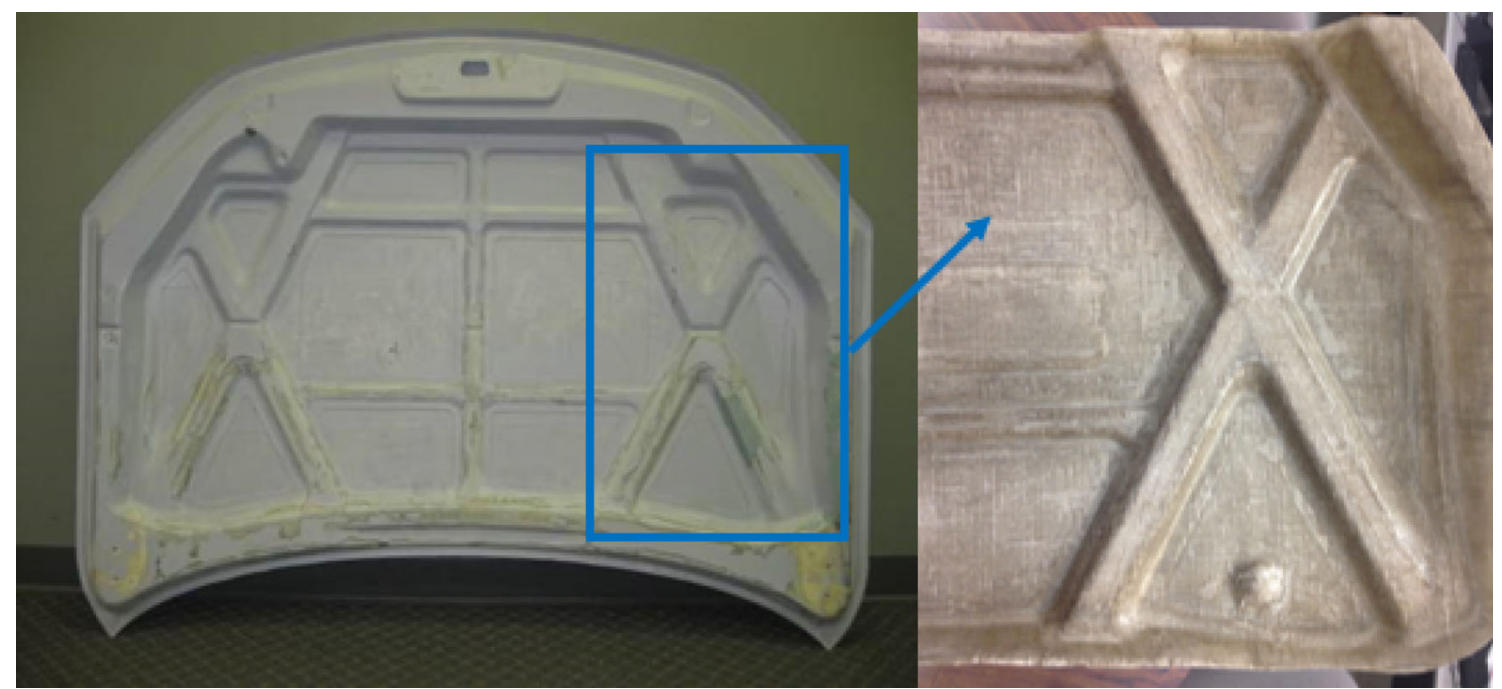

Fig. 3 Section of typical car hood panel studied in this research article

Fig. 4 a Front view of type-A sample, $\mathbf{b}$ back view of type-A sample, and c side view of the composite hood specimen without balsawood stiffening in the inner layer

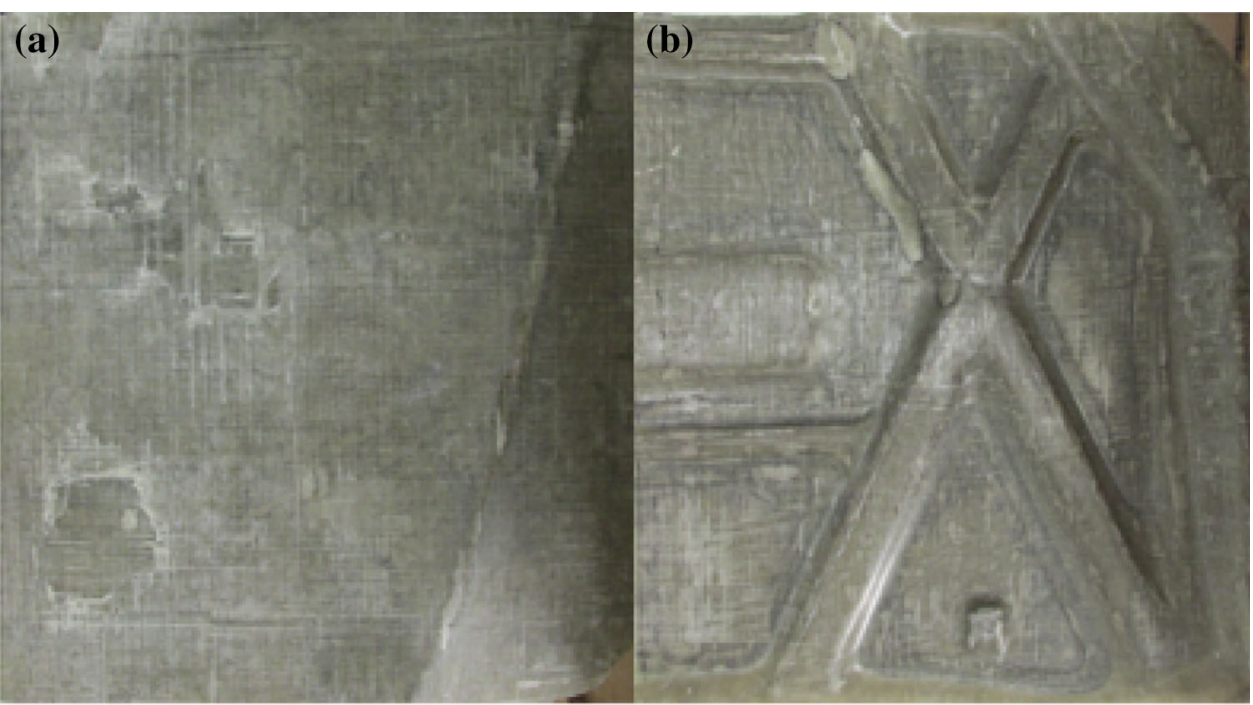

(c)

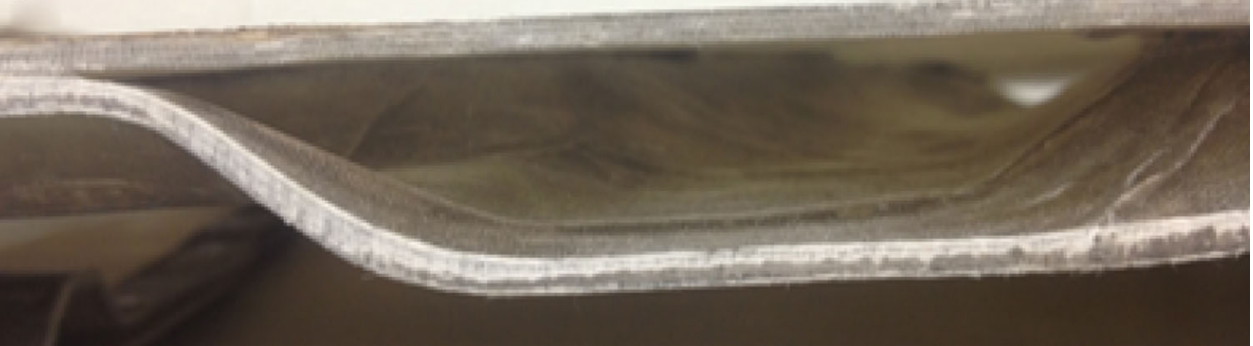

have been studied by Dost et al. [23]. It is found that the laminate stacking has significantly effect on compression after impact results. Caprino et al. [24] have conducted low-velocity impact tests on carbon/epoxy laminates with different thicknesses. Luo et al. [25] have studied an approach to evaluate the impact damage initiation and propagation in a composite plate. They have shown by introducing both threshold strength and propagation strength for matrix cracking, the main characteristics of impact damage can be predicted. Low velocity impact characteristics of different E-glass fibers reinforced thermoplastic and thermosetting matrix composites have been investigated by Sadasivam and Mallick [26]. The effects of material and geometric parameters on the mechanical 
Fig. 5 a Front view of type B sample, $\mathbf{b}$ back view of type $B$ sample, and $\mathbf{c}$ side view of type B specimen describing the location of balsawood core sandwiched between two E-glass/vinyl ester lower face sheets

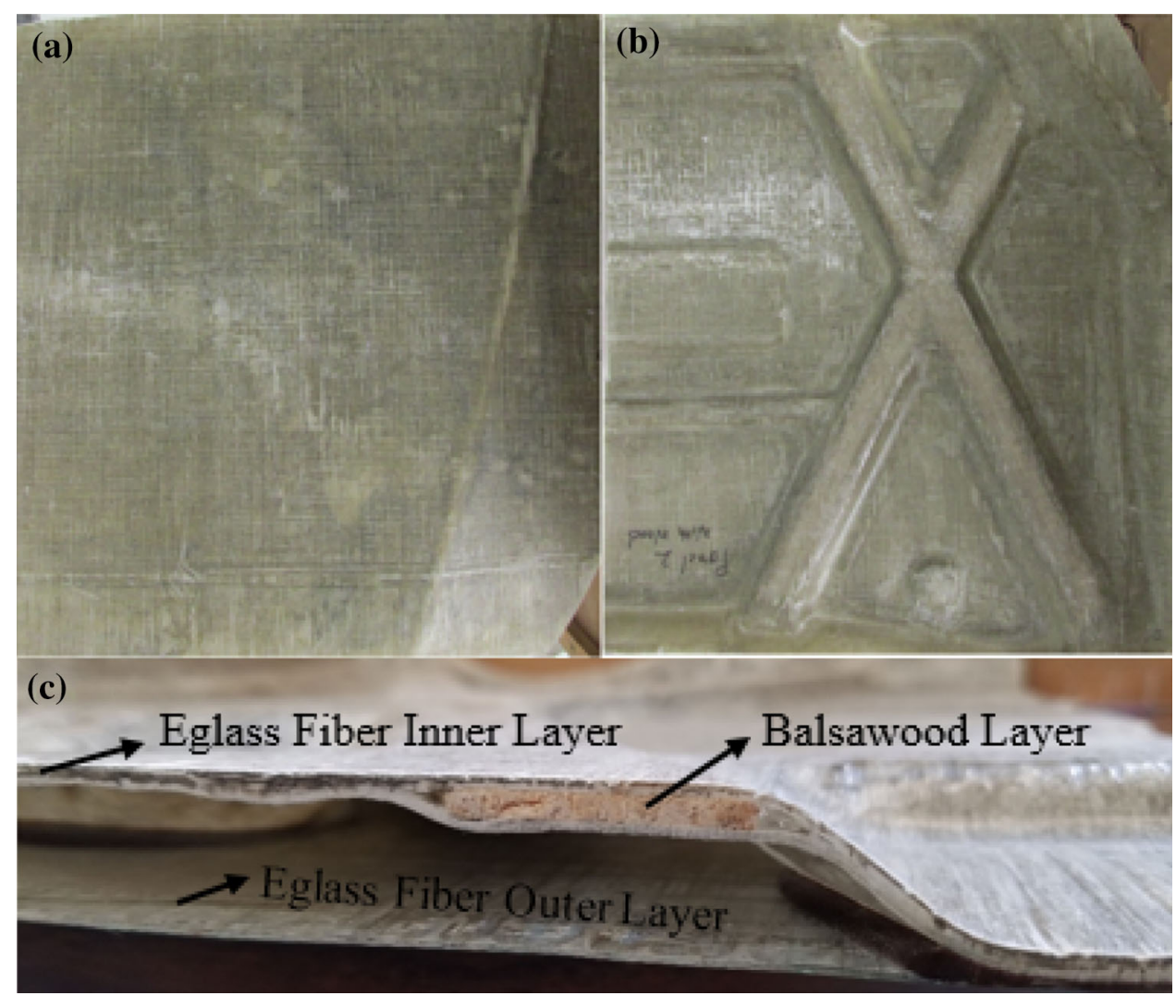

Table 1 Type of specimens studied in the research study

\begin{tabular}{lll}
\hline S.no & Specimen type & Nomenclature employed \\
\hline 1 & Composite car hood panel without stiffened inner layer with balsawood layer & Type-A \\
2 & Composite car hood panel having balsawood layer in the inner reinforcement layer & Type-B \\
\hline
\end{tabular}

Table 2 E-glass/vinylester properties

\begin{tabular}{|c|c|c|c|c|c|c|c|c|c|c|c|}
\hline Material & $\rho\left(\mathrm{kg} / \mathrm{m}^{3}\right)$ & $\mathrm{E}_{11}(\mathrm{GPa})$ & $\mathrm{E}_{22}(\mathrm{GPa})$ & $v_{21}$ & $\mathrm{G}_{12}(\mathrm{GPa})$ & $\mathrm{G}_{23}(\mathrm{GPa})$ & $\begin{array}{l}\mathrm{X}_{\mathrm{c}} \\
(\mathrm{MPa})\end{array}$ & $Y_{c}$ & $X_{t}$ & $Y_{t}$ & $\mathrm{~S}_{\mathrm{c}}$ \\
\hline E-glass/Vinylester & 1840 & 25.95 & 25.95 & 0.077 & 6.00 & 4.96 & 357 & 357 & 369 & 369 & 124 \\
\hline
\end{tabular}

Table 3 Balsawood core properties

\begin{tabular}{llllllllllll}
\hline Material & $\rho\left(\mathrm{kg} / \mathrm{m}^{3}\right)$ & $\mathrm{E}_{\mathrm{LT}}(\mathrm{GPa})$ & $\mathrm{E}_{\mathrm{TT}}(\mathrm{MPa})$ & $\mathrm{E}_{\mathrm{TC}}(\mathrm{MPa})$ & $\mathrm{G}_{\mathrm{LT}}(\mathrm{MPa})$ & $\mathrm{G}_{\mathrm{LR}}(\mathrm{MPa})$ & $\begin{array}{l}\mathrm{X}_{\mathrm{c}} \\
(\mathrm{MPa})\end{array}$ & $\mathrm{Y}_{\mathrm{c}}$ & $\mathrm{X}_{\mathrm{t}}$ & $\mathrm{Y}_{\mathrm{t}}$ & $\mathrm{S}_{\mathrm{c}}$ \\
\hline Balsawood & $96 \pm 5$ & 16.83 & 56 & 23.5 & 72.8 & 12.5 & 8.1 & 0.71 & 10.2 & 0.82 & 0.8 \\
\hline
\end{tabular}

response of graphite epoxy composite laminate under low velocity impact have been investigated by Cho and Zhao [27].
Most of the investigations that have been done in the literature were focused on studying the impact performance of composite materials using coupon level specimens. The 

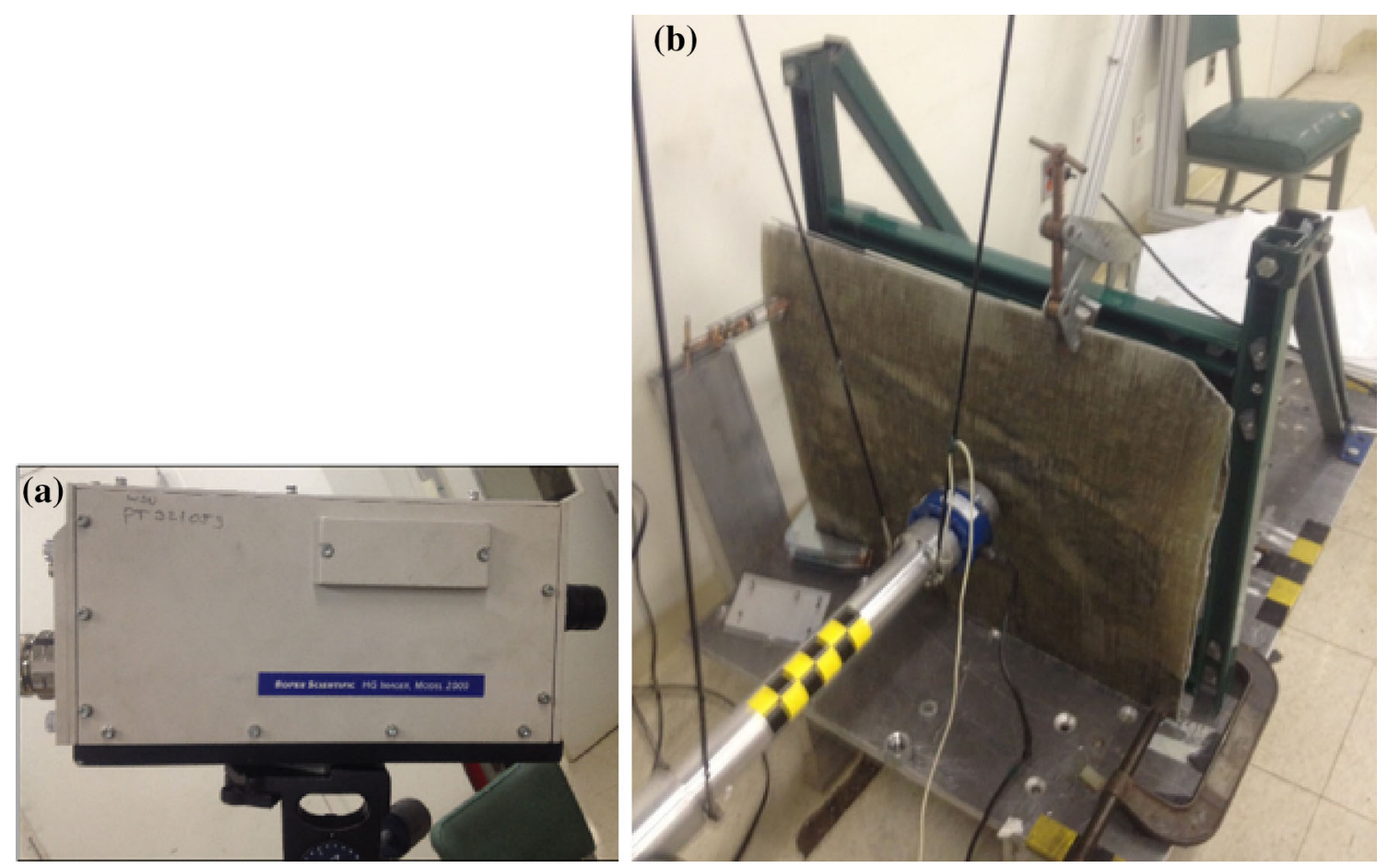

Fig. 6 a High speed camera used to detect the displacement of pendulum, b experimental setup

Fig. 7 Geometric dimensions of pendulum impactor in millimeters

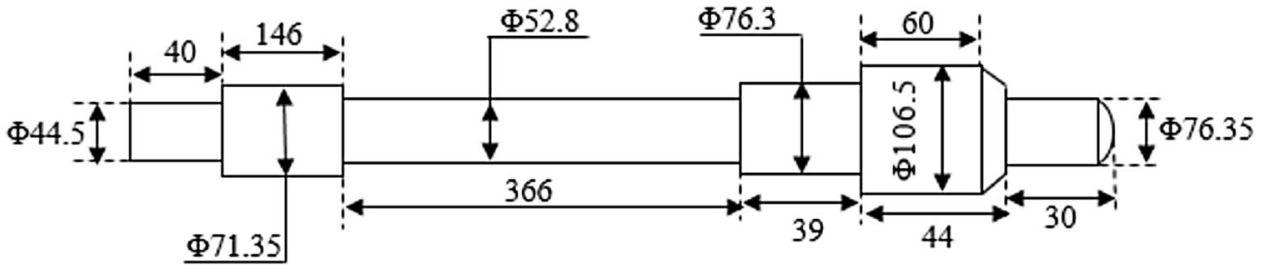

main purpose of this research study was to investigate the impact performance of automotive structural component manufactured by utilizing composite materials. A section of a typical car hood having reinforcement in its inner layer containing a common $\mathrm{X}$-shaped hat section was developed from e-glass/vinylester and balsawood composite materials for the structural analysis. The effect of stiffening the inner layer's reinforcement region by placing a balsawood layer in the X-shaped hat section was also studied. This investigation was done experimentally using pendulum impact for dynamic impact test and numerically using finite element code LS-DYNA to predict load-time, deflection-time, and kinetic energy-time response.

\section{Material Description and Specimen Manufacturing}

The composite laminate and sandwich composite samples of car hood were developed by MAG Industrial Automated Systems. A section of a typical hood inner panel reinforcement containing a common X-shaped hat section was selected for structural analysis. The hat section pattern was approximately $450 \mathrm{~mm}$ x $380 \mathrm{~mm}$. A soft tool for each part was created by creating a "splash" off the outer and inner panel from the steel production hood. From the splash, a soft mold is created (See Fig. 1) that represents the show surfaces of the hood outer and inner surfaces.

The test panels were produced by manually applying/ layering the composite prepreg ply's (Fig. 2a) in a 0-90-900 orientation in the appropriate area on the soft tool surface. The prepreg material is comprised of E-Glass fiber reinforcement (68\% Glass fiber content by weight) and a Vinyl Ester monomer free polymer. The regular balsa samples (Fig. 2b) of a constant thickness $(2.2 \mathrm{~mm})$ were trimmed to fit and placed between the material plies at the top of the hat section only. Then the final layers of material were manually applied across the X-section area to complete the inner panel sample. Once the layups were complete the layup and took surface are vacuum bagged and placed in a large convection oven for $1 \mathrm{~h}$ at $149^{\circ} \mathrm{C}$ to facilitate the curing phase of the prepreg polymer. The 


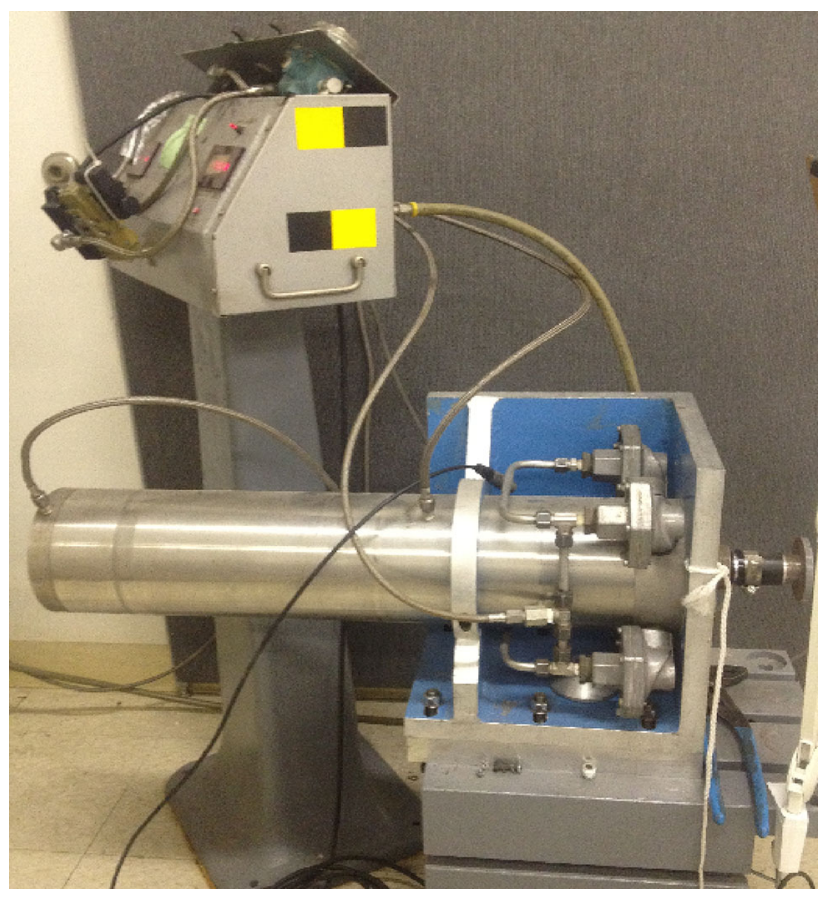

Fig. 8 Pneumatic cylinder used to drive pendulum

corresponding outer panel of the hood section was also produced in the same manner and ply orientation. The outer and inner panels samples were bonded together using a 2 component adhesive to complete the closed hat, $\mathrm{X}$ pattern for testing. The bond gap was established by utilizing glass beads applied to the glue line to ensure a consistent bond gap at $.75 \mathrm{~mm}$. The individual thickness of E-glass/vinyl ester face sheet was $0.381 \mathrm{~mm}$. The stacking sequence used in composite laminate car hood samples was [0/90/90/0] s. The E-glass prepreg and regular balsawood used in the samples are shown below:

A section of typical car hood panel studied in this research article is illustrated in Fig. 3 with the help a rectangle drawn around it. The front, back and side views of both types of composite car hood before impact test are shown in Figs. 4 and 5. Table 1 describes the nomenclature employed in the impact histories of composite car hood panels. Balsa wood sandwiched between the lower sheets is described in Fig. 5c. The balsawood panels does not cover the curvature of $\mathrm{X}$ shaped region because of which it appears in Fig. 5c that it only covers partial width of inner stiffening layer.

\section{Preliminary Material Testing}

Finite element analysis requires all the basic properties of the material and its behavior under various loading conditions. Hence, preliminary tests were conducted on the material to evaluate the properties under tests such as tensile, compression and shear. The strain rate effect were not considered in this research study as the eglass fiber/ vinylester laminated composites does not show strain rate dependency at low impact velocities $(<10 \mathrm{~m} / \mathrm{s})$. These tests are done on both skin and core materials in different directions as the materials are considered to be anisotropic. Preliminary tests were performed after referring ASTM D3039, ASTM 6641 and ASTMD5371 for tensile, compression and in-plane shear tests. All these tests for the E-glass/toughened vinyl ester face sheets were conducted at MAG company location. The constitutive material properties for the balsawood were taken from the previous research work conducted in an advanced composite research lab at Wayne state university [28]. The properties of E-glass/Vinyl-ester and balsa wood core used as input in FEA are summarized in Tables 2 and Table 3 respectively. The properties reported in Table 2 are the characteristics of a laminate having same stacking sequence as the specimens used in this research.

\section{Experimental Analysis}

Low velocity impact tests were performed by impacting an aluminum pendulum having a mass of $6.2 \mathrm{~kg}$. and at a velocity of $4.1 \mathrm{~m} / \mathrm{s}$. A load cell was placed at the front of the pendulum to record the force during the experiment. An accelerometer was attached to pendulum to record the acceleration data at an interval of $0.0001 \mathrm{~s}$. The samples were clamped by using c-clamps at all four corners to the rigid frame. The experimental set up including fixture used to hold the specimen and pendulum with a load cell and accelerometer are shown in Fig. 6b. The pendulum dimensions and shape used for impacting the car hood samples is described in Fig. 7. A pneumatic device as shown in Fig. 8 was used to power the pendulum by adjusting the air pressure equal to $550 \mathrm{kPa}$. The pendulum was held manually to prevent repeated impacts.

The impact force and the acceleration data were collected for the different panels by using the load cell and accelerometer place at the front of the pendulum. The high speed camera (Kodak 4540) shown in Fig. 6a was also employed to get the displacement data at 5000 fps by tracking the pendulum movement in the video through the Image tracking software. This displacement values was taken to check the accuracy of displacement values that we get from the acceleration data of pendulum. Good agreement was observed between the both displacement values. An experimental simulation of pendulum hitting the specimen is displayed in Fig. 9 by using snapshots at various intervals of the impact test. The test matrix involves the testing of three samples of each category of specimens at $4.1 \mathrm{~m} / \mathrm{s}$ impact velocity. The impact point on the front side was set close to the $\mathrm{x}$ section cross point as demonstrated in Fig. 10. 


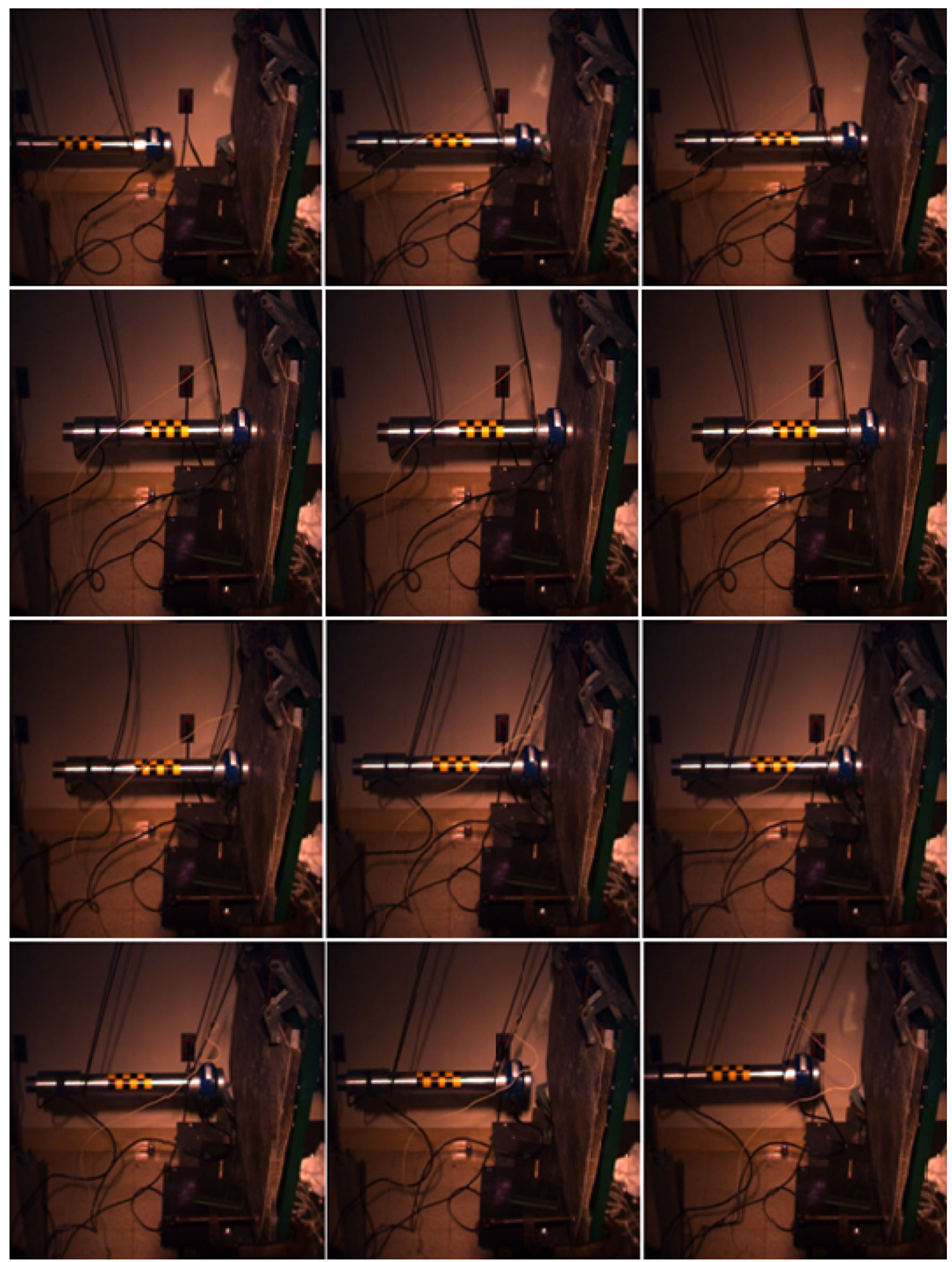

Fig. 9 Experimental simulation snaps from high speed camera

\section{Finite Element Analysis}

Modeling and analysis of composite material is complex, as they include several parameters. It is important to understand all the aspects of composite behavior before choosing and implementing in the material model. A nonlinear finite element analysis package, LS-Dyna has extensive material models for composite materials along 


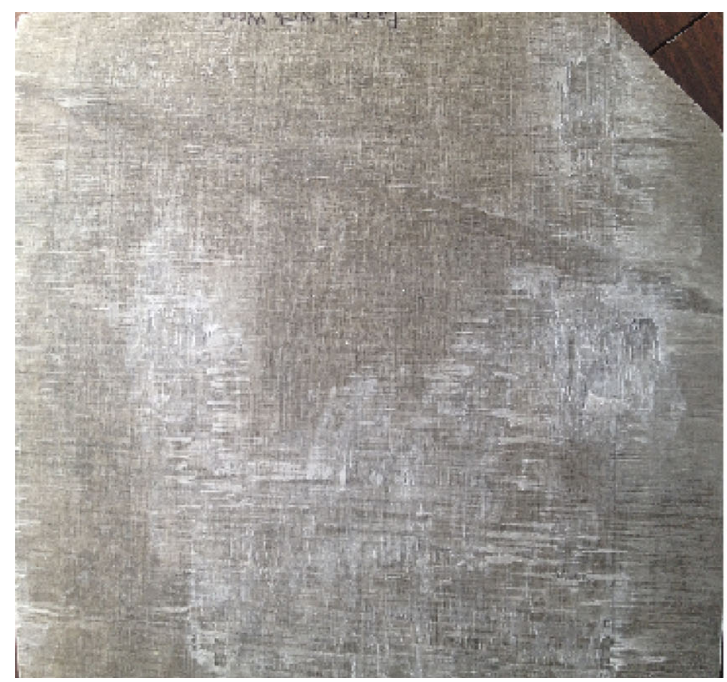

Fig. 10 Impact point location

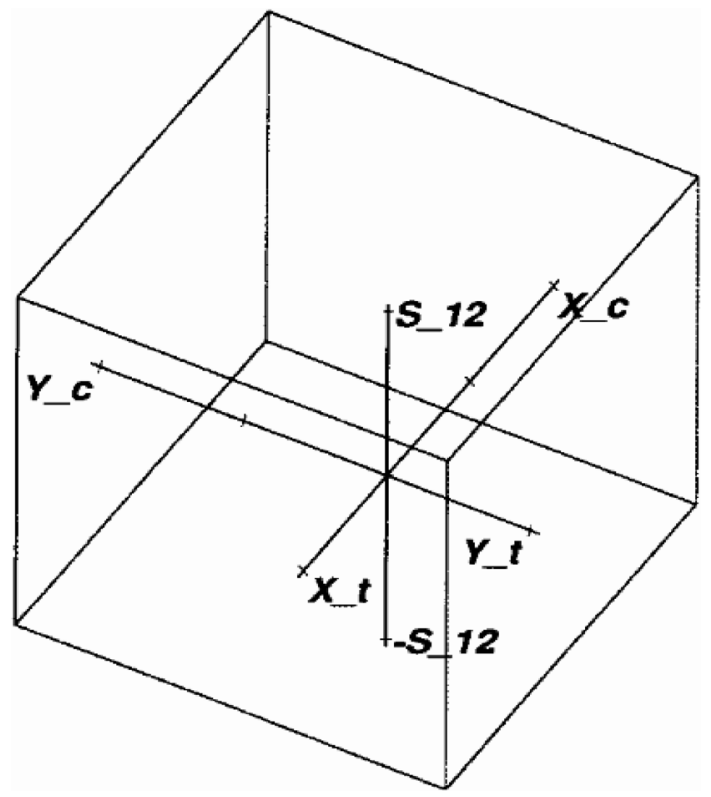

Fig. 11 Failure model used in Mat 59 of LS-Dyna. [29]

with failure modes. Hood cross section panels that were investigated experimentally are analyzed using FEA for further understanding of failure mechanisms. The finite element model was developed from the surface CAD model for lower skin provided in IGES file format by MAG Company.

The skins are modeled with 4-node shell elements as the thickness is less as compared with balsawood core thickness, which has been modeled with 8-node solid elements. A pre-processor, hyper mesh software was used to construct the model.
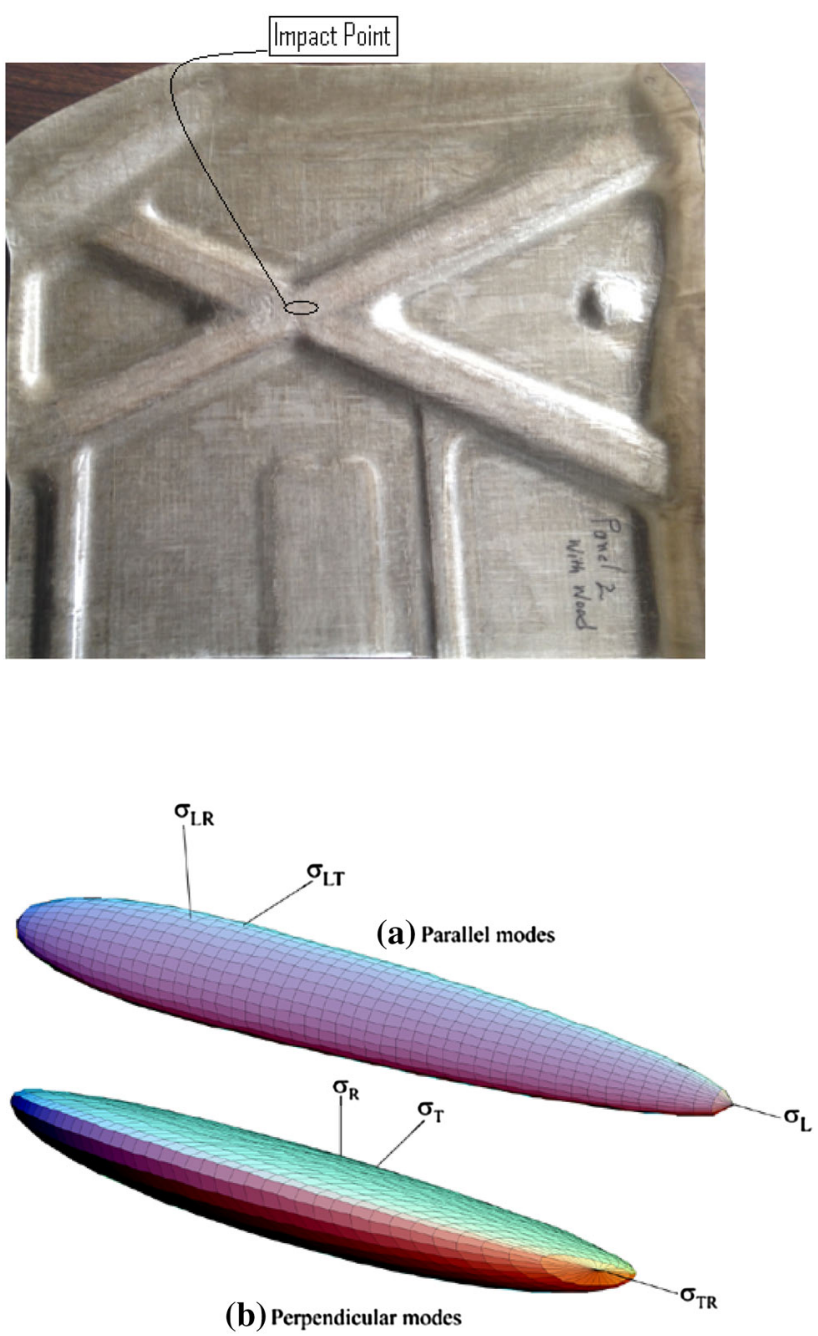

Fig. 12 Yield criteria for wood (Mat 143) material model [31]

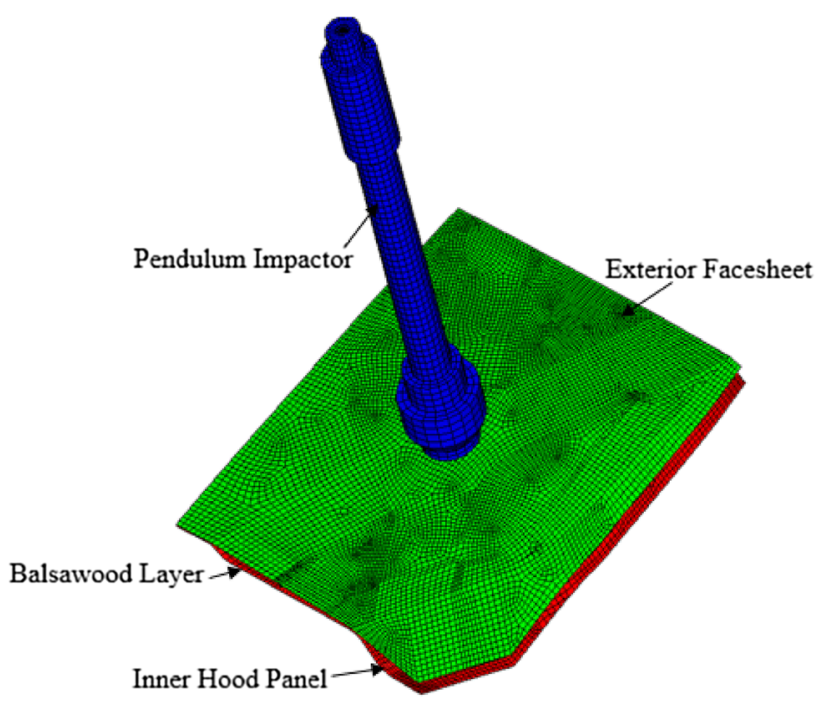

Fig. 13 Finite element analysis model 

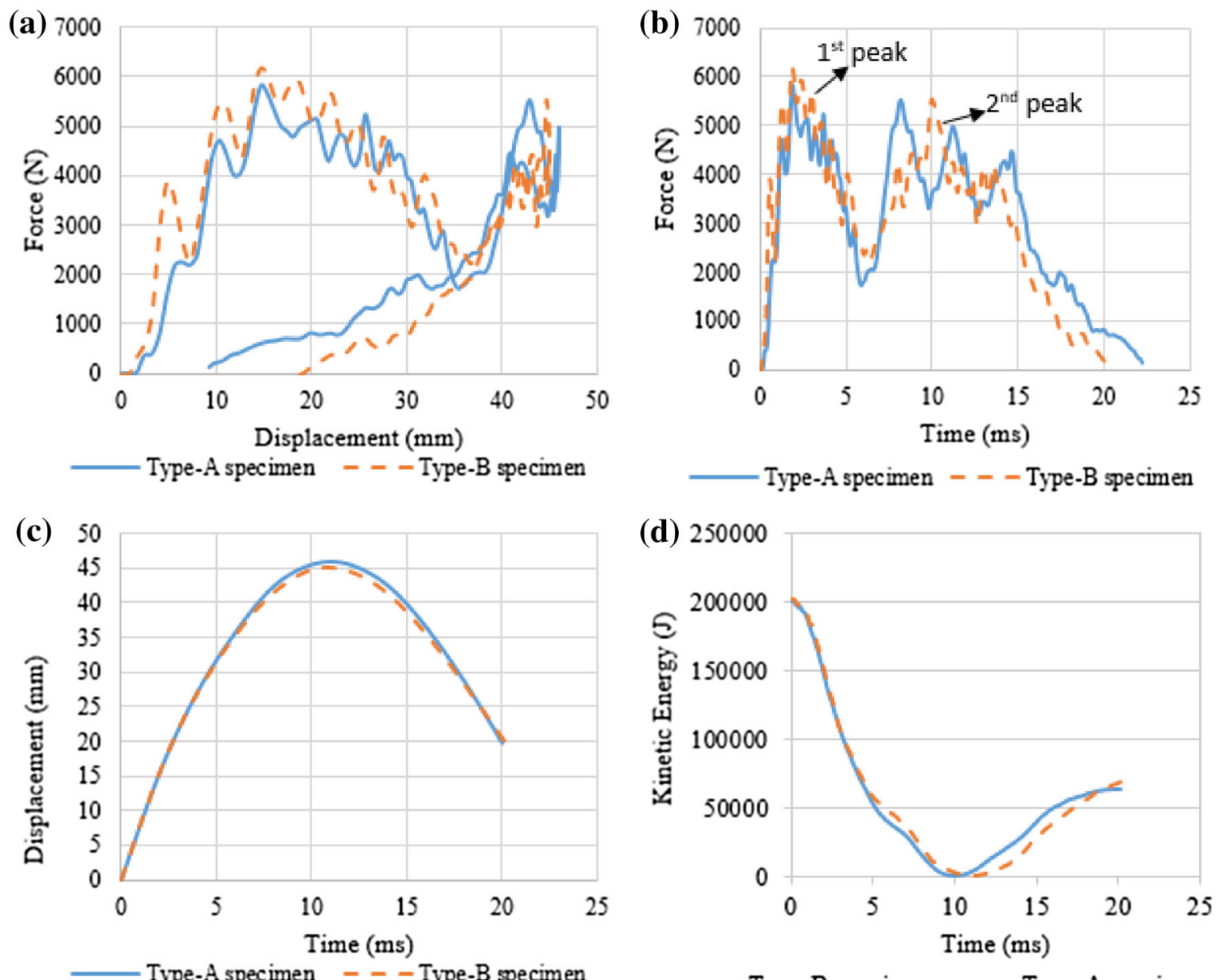

Fig. 14 Comparison between typical impact test histories of both type of specimens a force-displacement plot, b force-time plot, c displacement-time plot, $\mathbf{d}$ kinetic energy versus time curve

Fig. 15 Sectioned view of FEM model showing the occurrence of contact between two layers of the composite hood sample

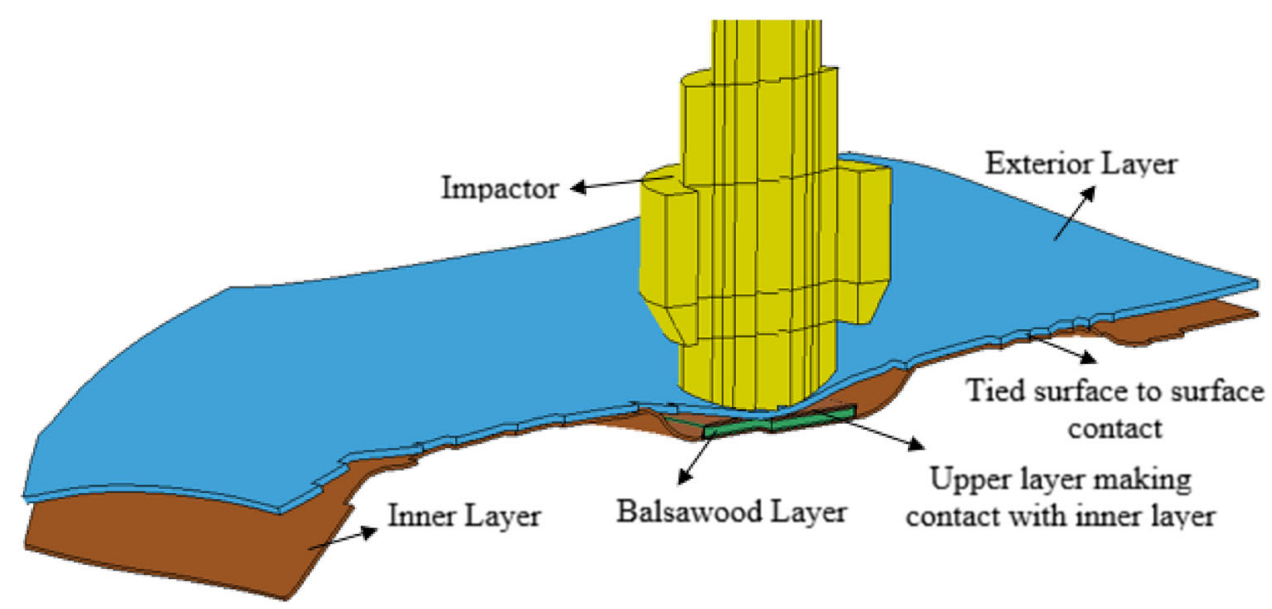

\section{Eglass/Vinylester Laminate Material Model}

Composite failure shell model, MAT 59 was assigned for both the upper skin and lower skin. The material model 59, which is composite failure shell model, has faceted failure surface as shown in Fig. 11. Ply-by-ply orientation of skin is not available in this model and laminate properties were directly applied. This is a an elastic-plastic material in which strength values in all orthotropic directions along with the shear strength are considered in the yield function. 
Table 4 Peak forces and displacement of specimens

\begin{tabular}{llllll}
\hline S.no & Panel type & $\begin{array}{l}\text { First peak } \\
\text { load }(\mathrm{N})\end{array}$ & $\begin{array}{l}\text { Second peak } \\
\text { load }(\mathrm{N})\end{array}$ & $\begin{array}{l}\text { Forward } \\
\text { displacement }(\mathrm{mm})\end{array}$ & $\begin{array}{l}\text { Rebound } \\
\text { displacement }(\mathrm{mm})\end{array}$ \\
\hline 1 & Type-B specimen & 5439 & 6182 & 42.85 & 11.95 \\
2 & Type-A specimen & 5263 & 5269 & 45.79 & 9.2 \\
\hline
\end{tabular}
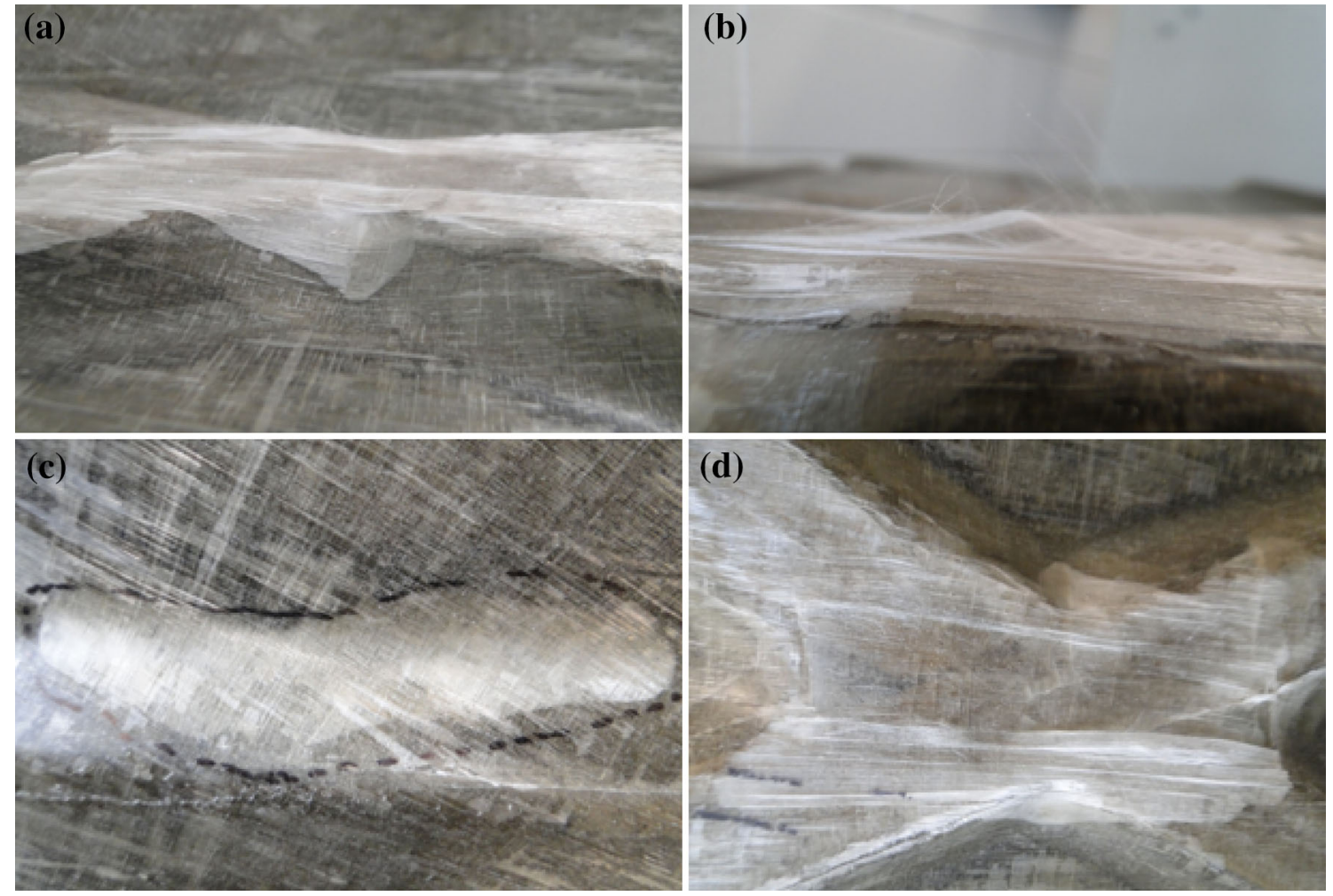

Fig. 16 Failure modes: a cracks in exterior laminate face sheet layer, $\mathbf{b}$ fiber breakage and matrix rupture in inner laminated face sheet layer, c delamination between successive plies observed in sandwich composite layers, and $\mathbf{d}$ excessive failure in inner e-glass/vinyl ester layer

This results in faceted surface envelope. The transverse shear is also considered in this model. Setting the value of $\alpha$ to a certain values allows to limit the tensile part of the failure surface after the first tensile failure. Considering the values of $\alpha=0$, sets the tensile strengths to zero after the failure and thus only shear and compressive loads can be carried after the corresponding failure. The failure surface equations are described below.

$$
\begin{aligned}
& \sigma_{1 \mathrm{t}}=\alpha X_{\mathrm{T}}, \\
& \sigma_{1 \mathrm{c}}=-X_{\mathrm{C}}, \\
& \sigma_{2 \mathrm{c}}=\alpha Y_{\mathrm{T}}, \\
& \sigma_{2 \mathrm{c}}=-Y_{\mathrm{C}}, \\
& \sigma_{12}=\sigma_{23}=\sigma_{13}= \pm S_{\mathrm{C}} .
\end{aligned}
$$

\section{Wood Constitutive Material Model}

Mat 143, Wood model was assigned to balsawood core layer. Wood material model, Mat 143 that exhibits transversely isotropic property is applied to the core elements. Softening and fracture parameters are not considered which are available in this material model [30], as it needs more research on balsawood. Yield criteria are formulated parallel and perpendicular to the grain from tensile, compressive and shear strength of balsa in parallel and a perpendicular direction to the grain. The yield criterion [29] is composed of two terms having two of the five stress invariants of a transversely isotropic material for parallel modes. These invariants are $\mathrm{I}_{1}=\sigma_{11}$ and $\mathrm{I}_{4}=\sigma_{12}^{2}+\sigma_{13}^{2}$. According to this criterion the yielding occurs when $f_{\|} \geq 0$, where 

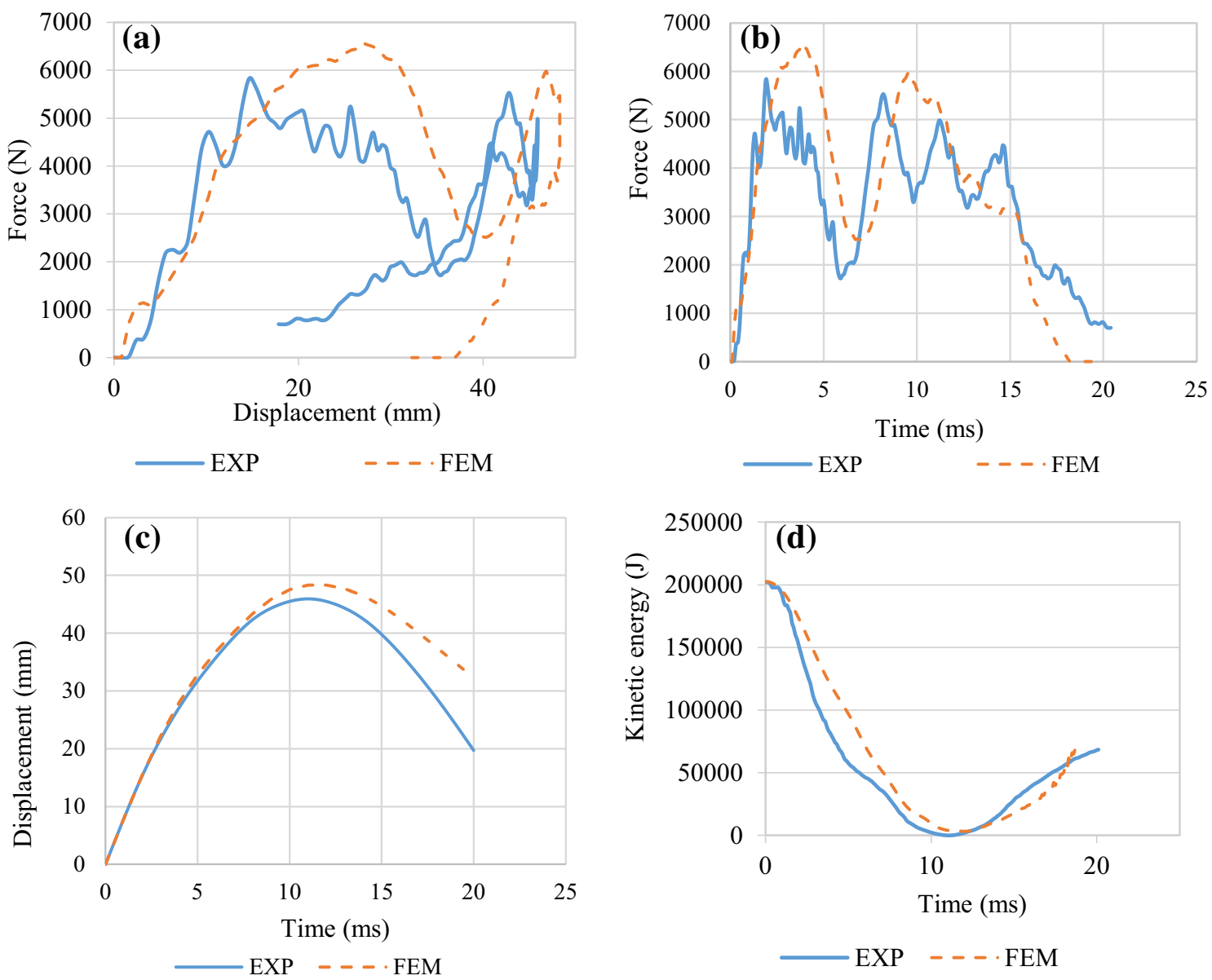

Fig. 17 Comparison between typical experimental and FEM impact histories of type-A specimens a force-displacement plot, b force-time plot, c displacement-time plot, and $\mathbf{d}$ kinetic energy versus time curve

$f_{\|}=\frac{\sigma_{11}^{2}}{X^{2}}+\frac{\left(\sigma_{12}^{2}+\sigma_{13}^{2}\right)}{S_{\|}^{2}}-1 \quad X=\left\{\begin{array}{ll}x_{t}, & \sigma_{11}>0 \\ x_{c}, & \sigma_{11}<0\end{array}\right.$.

The yield criterion in the perpendicular modes also contains two stress invariants of a transversely isotropic material such as $I_{2}=\sigma_{22}+\sigma_{33}$ and $I_{3}=\sigma_{23}^{2}-\sigma_{22} \sigma_{33}$. The yielding occurs when function, $f_{\perp} \geq 0$ where

$$
\begin{gathered}
f_{\perp}=\frac{\left(\sigma_{22}+\sigma_{33}\right)^{2}}{Y^{2}}+\frac{\left(\sigma_{23}^{2}-\sigma_{22} \sigma_{33}\right)}{S_{\perp}^{2}}-1 \\
Y=\left\{\begin{array}{ll}
Y_{t}, & \sigma_{22}+\sigma_{33}>0 \\
Y_{c}, & \sigma_{22}+\sigma_{33}<0
\end{array} .\right.
\end{gathered}
$$

Here $\mathrm{X}$ and $\mathrm{Y}$ are the strengths parallel and perpendicular to the grain, respectively, and $\mathrm{S}$ is the shear strength and $x_{t}$ is tensile strength parallel to the grain, $x_{c}$ is Compressive strength parallel to the grain, $Y_{t}$ is Tensile strength perpendicular to the grain, $Y_{c}$ is Compressive strength perpendicular to the grain, $S_{\|}$is the shear strength parallel to the grain and $S_{\perp}$ is the Shear strength perpendicular to the grain. Once the yield criteria are met, the stress components are limited by the plasticity algorithms by returning the trial elastic stress back to the yield surface. Return mapping algorithm in the material model divide the stress and strain tensors into elastic and plastic parts and thus enforces the plastic consistency condition. The smooth surfaces produced by wood material yield criteria are shown in Fig. 12.

The strain rate effect were not considered in the constitutive material models as the eglass fiber/vinylester laminated composites does not show strain rate dependency at low impact velocities $(<10 \mathrm{~m} / \mathrm{s})$, which is the case in this research. LS-Dyna theory manual [31] can be referred for detailed information about plasticity consistency condition, consistency parameters and stress modification algorithm employed at each time step. The impactor which is having the different cylindrical diameters as shown in Fig. 13 is modeled as rigid solid elements. The impactor was made rigid; Mat 20. The upper and bottom skins were fixed in all six-degrees of freedom at all four corners. Tied surface to surface contact is considered 

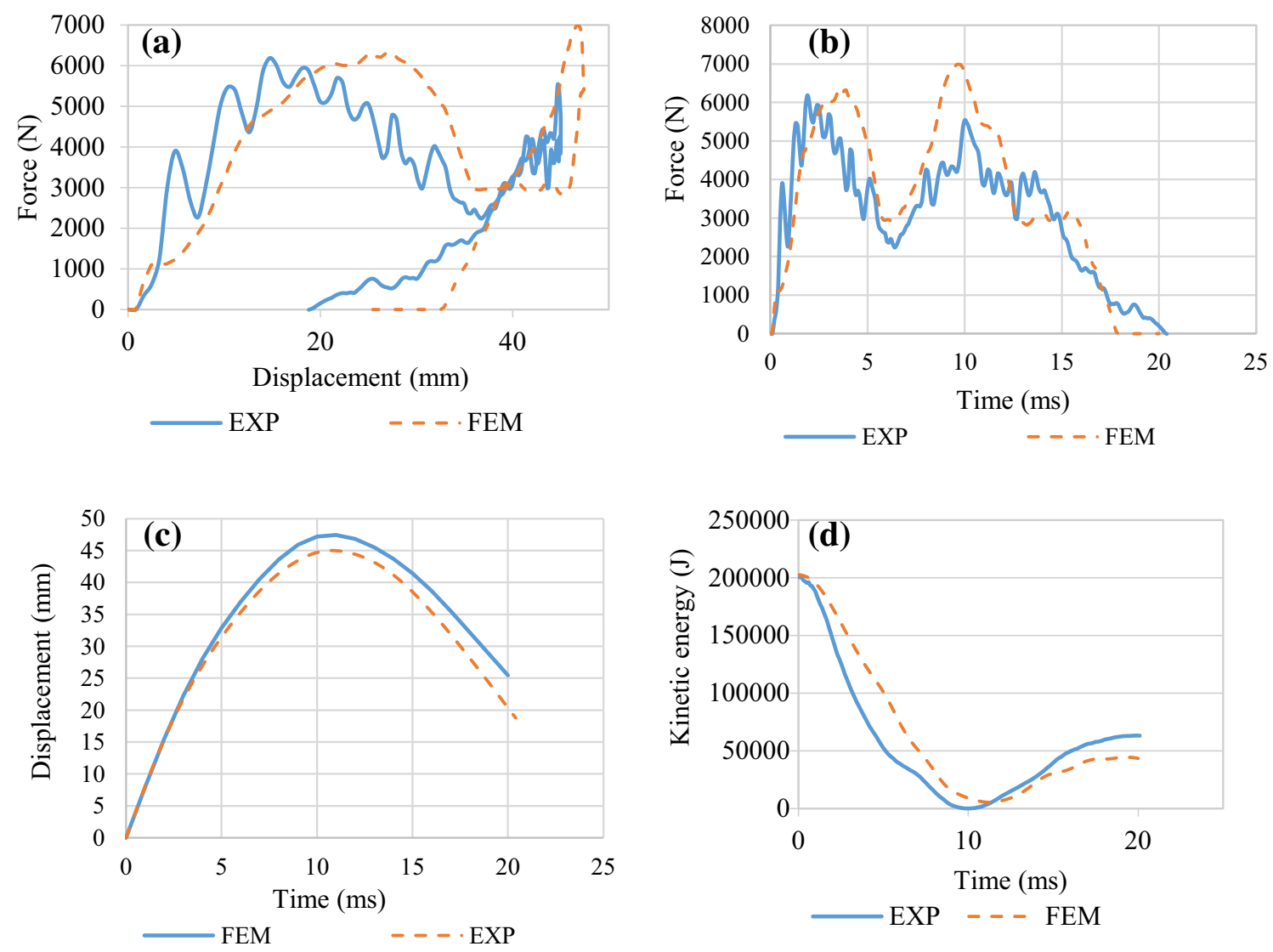

Fig. 18 Comparison between typical experimental and FEM impact histories of type-B specimens a force-displacement plot, $\mathbf{b}$ force-time plot, c displacement-time plot, and $\mathbf{d}$ kinetic energy versus time curve
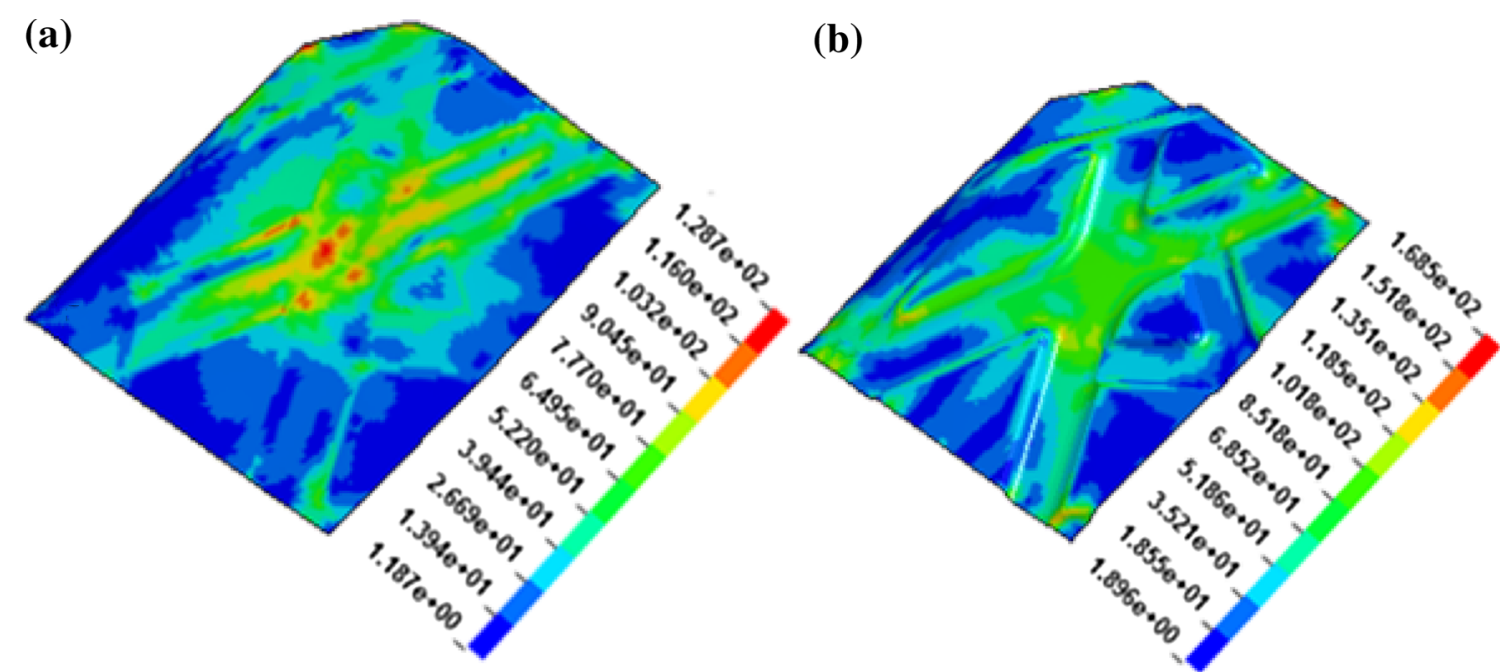

Fig. 19 Effective Von Mises stress (MPa) contour of Type-A specimen (time $=4 \mathrm{~ms}$ ). a Upper E-glass/vinyl ester layer and b inner e-glass/ vinyl ester layer

for connecting the upper and bottom skin in the first case and connecting balsa wood core to skins in the second case. Automatic surface to surface contact type was given between the Impactor, top skin, balsawood core and bottom skin. Finite element mesh of the model is shown in Fig. 13.

\section{Results and Discussion}

The impact response of both types of specimens was compared to each other to study the effect of balsawood layer which was used to increase the bending rigidity of the 


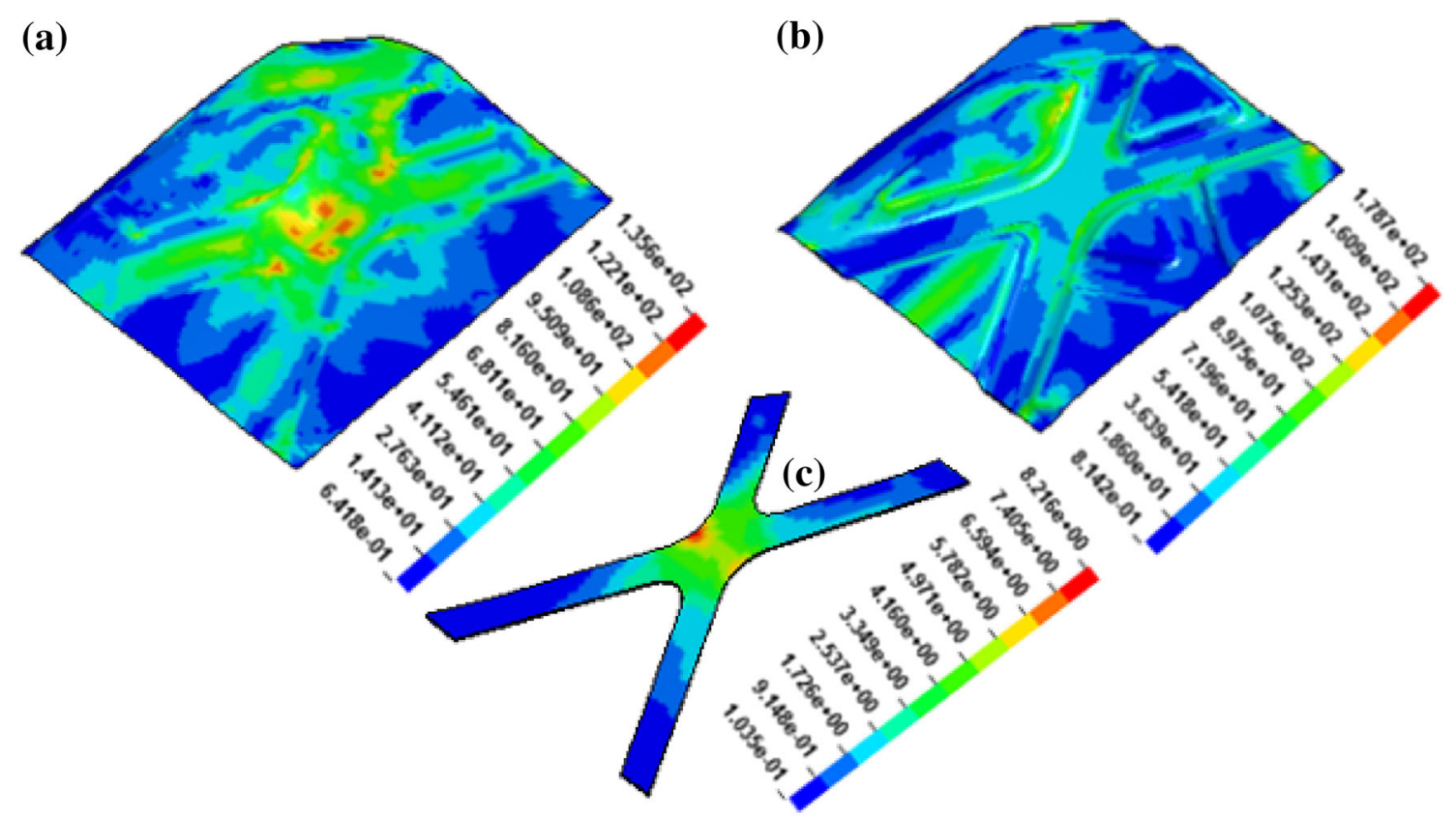

Fig. 20 Effective Von Mises stress (MPa) contour of Type-B specimen (time $=4 \mathrm{~ms}$ ). a Upper E-glass/vinylester layer, b inner e-glass/ vinylester layer, and $\mathbf{c}$ Balsawood layer

Table 5 Comparison between FEA and experimental peak forces

\begin{tabular}{llllll}
\hline S.no & Panel type & $\begin{array}{l}\text { Experimental first } \\
\text { peak load }(\mathrm{N})\end{array}$ & $\begin{array}{l}\text { Experimental second } \\
\text { peak load }(\mathrm{N})\end{array}$ & $\begin{array}{l}\text { FEA first } \\
\text { peak load (N) }\end{array}$ & $\begin{array}{l}\text { FEA second } \\
\text { peak load }(\mathrm{N})\end{array}$ \\
\hline 1 & Type-B specimen & 5439 & 6182 & 5830 & 6910 \\
2 & Type-A specimen & 5263 & 5269 & 6550 & 5400 \\
\hline
\end{tabular}

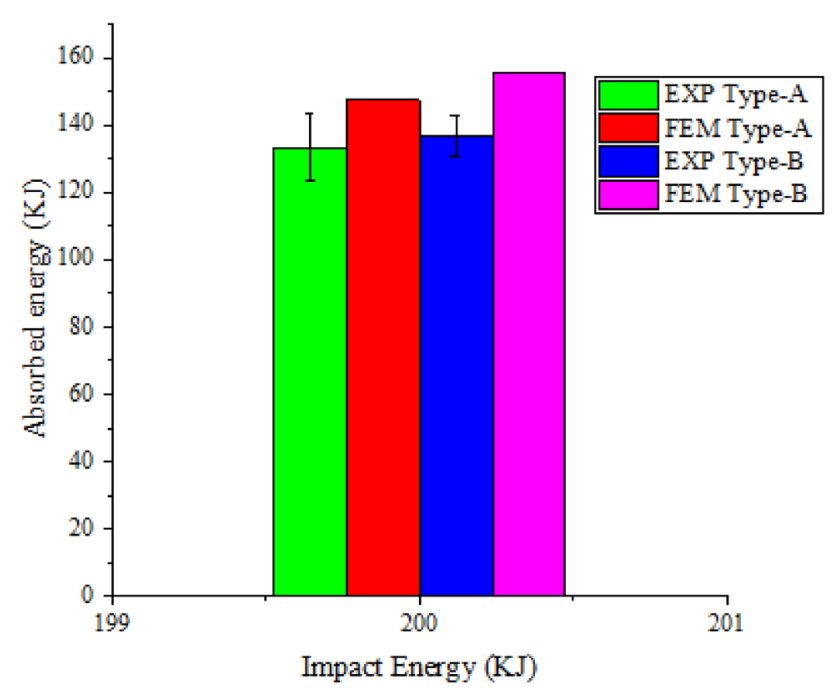

Fig. 21 Absorbed energy comparison between FEA and experimental results

inner layer of specimens. Impact histories of both types of specimens are plotted in Fig. 14. Not a significant difference was notice in the performance of specimens having balsawood reinforcement in their inner layer. This may be due to the factor that inner layer of specimens does not directly come into the picture at impact energy level used in this study because the majority of energy was observed by exterior layer only, as the pendulum impactor hits the outer layer first. Two peaks were observed in the forcedisplacement and force time histories of both specimens as shown in Fig. 14. The second peak occurs in the impact histories at the time when exterior layer touches the inner reinforcement layer and the force is exerted on the impactor after reduction in strength of outer layer.

The force-time impact history indicates the occurrence of the second peak around the $6 \mathrm{~ms}$. Finite element analysis and high speed cinematography employed during impact verified the occurrence of this phenomenon. A view graph was selected from finite element analysis to demonstrate this effect and is shown in Fig. 15. The addition of balsawood reinforcement to the inner layer showed slightly higher peak force and smaller contact duration. Average peak forces and displacement characteristics of both types of specimens are compared in Table 4. The effect of balsawood reinforcement in the inner layer comes into picture 


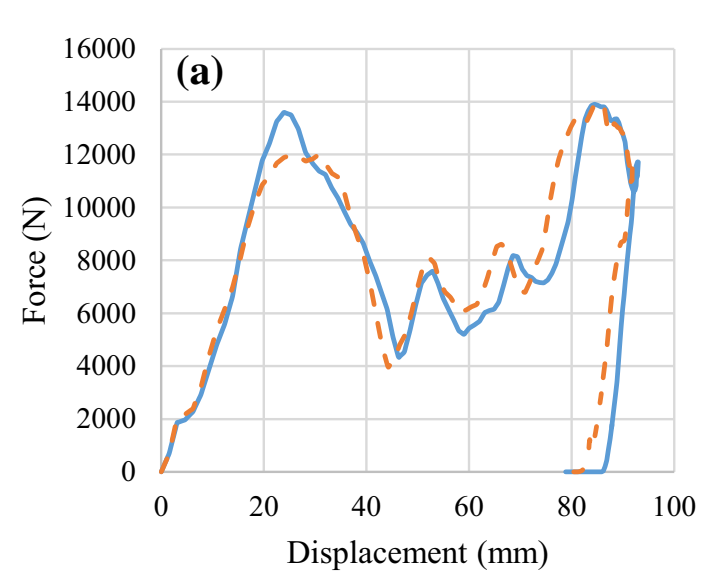

TYPE-B --- TYPE-A

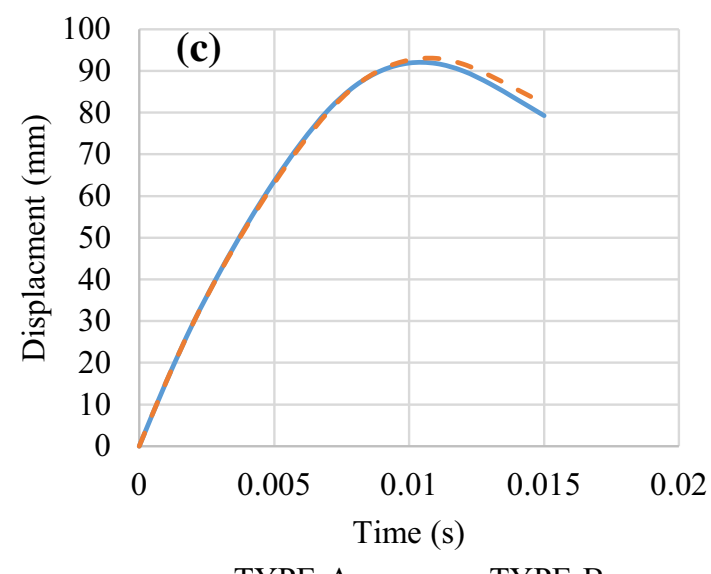

TYPE-A - - - TYPE-B
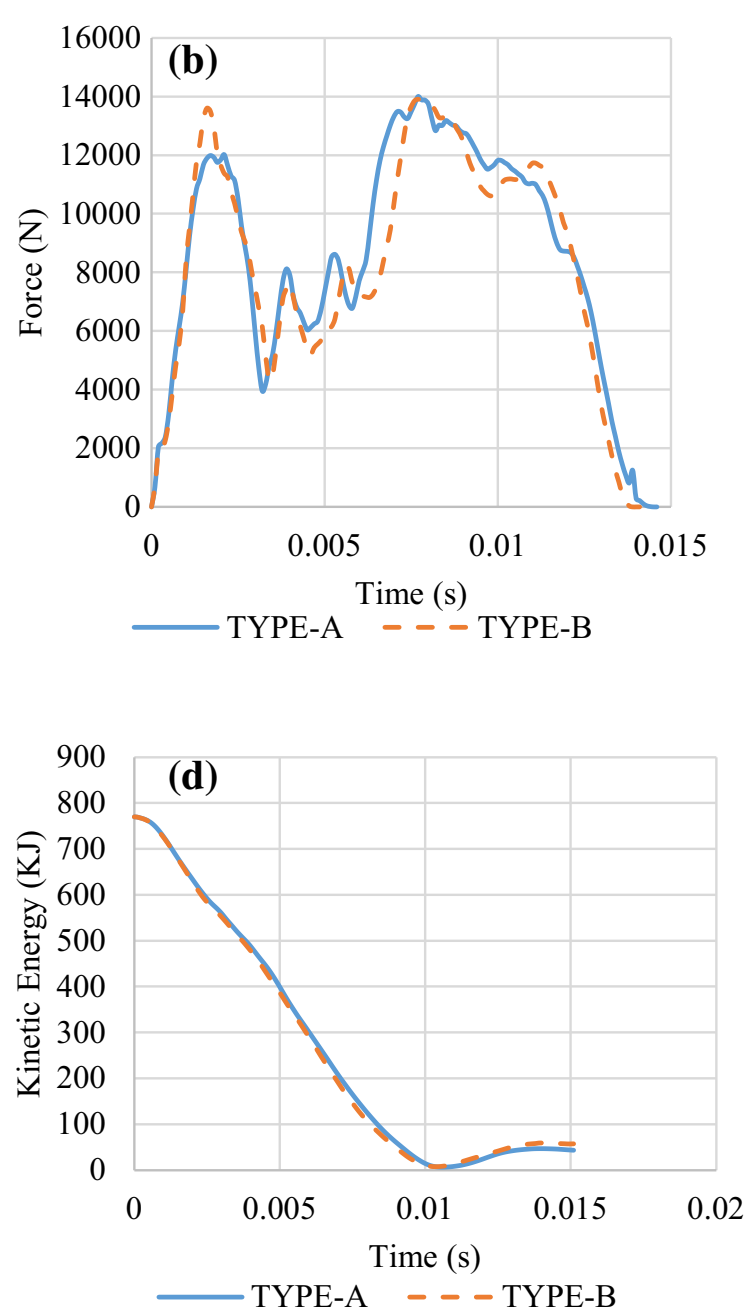

Fig. 22 Comparison between typical impact test histories of both type of specimens impacted at $15.6 \mathrm{~m} / \mathrm{s}$ velocity a force-displacement plot, b force-time plot, $\mathbf{c}$ displacement-time plot, and $\mathbf{d}$ kinetic energy versus time curve

in the form of higher second peak force and larger rebound displacement.

Failure modes in a car hood panels observed under impact loading in this study include fiber failure, matrix rupture, and delamination between the successive plies. The typical failure modes that occurred around the $\mathrm{X}$ section of car hood panel are shown in Fig. 16.

A comparison between finite element analysis results and experimental impact histories for type-A and type-B specimens are shown in Figs. 17 and 18, respectively. FEA model predicts slightly higher force for the first peak and has reasonable agreement with experimental value for the second peak in the case of type-A specimens. Loading portion of FEM force-displacement plot was found out to have good agreement with the experimental graph but it over predicts the rebound displacement in the unloading portion of the graph. The kinetic energy vs time plots shows excellent match with the experimental results.
In the case of type-B specimens, FEA model shows reasonable agreement with the experimental plot for the first peak but overestimated the force value in the second peak. The displacement vs time and kinetic energy vs time curves were predicted by finite element analysis with adequate accuracy. The rebound portion of the force-displacement curve shows slight discrepancies when compared with the experimental result.

Effective Von Mises stress contours for individual layers of both types of specimens were obtained from LSDyna FEA analysis at simulation time around $4 \mathrm{~ms}$. The impactor forces the upper layer to make contact with inner layer around this time and the occurrence of the second peak happens in the force-time plots around this time. The stress contours for type-A and type-B specimens are plotted in Figs. 19 and 20, respectively. The larger stress values in the upper layers of specimens indicate that the majority of impact energy was absorbed by this layer during an impact 
event at impact velocity used in this study. A comparison between FEA and experimental results for the averaged peak forces observed during this study is tabulated in Table 5.

A comparison between FEA and experimental results for the energy absorption capabilities of both type of specimens studied in this research is illustrated in Fig. 21. The absorbed energy was estimated by calculating the area under the force-displacement curves with the origin, graphing and analysis software.

The finite element simulations was conducted at higher velocity to better understand behavior of balsawood layer at increased impact energy. Impact velocity was increased to $15.6 \mathrm{~m} / \mathrm{s}$ in this case. Figure 22 illustrates the comparative behavior of both types of laminates at higher impact energy.

Minimal effect of balsawood was observed on the impact characteristics of specimens even with the increase in the impact velocity. The increase in velocity resulted in higher impact force at first peak in the case specimen having balsawood layer. Kinetic energy and displacement of both types of specimens were almost similar at higher impact energy also. Higher thickness of balsawood layer would result in increased diversity among the results of both cases.

\section{Conclusions}

Practical sandwich composites with E-glass vinyl ester skins and balsawood core were produced and investigated for structural performance under impact loading. Computational procedures were developed to predict the impact performance of the automotive structures with sandwich constructions. The use of balsawood does not significantly added value in the energy absorption as the thickness of the balsawood was comparatively small. Experimental and predicted results matched well in terms of load-deflection response and kinetic energy. This study has demonstrated that light weighting via sandwich constructions can be achieved and predictive tools are in place to allow utilization of this technology for automotive composite parts. This study provides new information about lightweight sandwich composites for potential application in automotive industry with greater confidence.

Acknowledgments The authors acknowledge funding for this work through the DOE's Lightweight Automotive Materials Program (LAMP) administered by NCMS (Mr. Steven Hale-Program Manager). We also acknowledge Jim Dallam and Daniel Allman of MAGias for the composite skin prepregs that are provided to us. Also, we thank Robert Graybill of Nimbis Services for allowing us to utilize OSC HPC portal for our FEA analysis.

\section{References}

1. Saito H, Kimpara I (2006) Evaluation of impact damage mechanism of multi-axial stitched CFRP laminate. Compos Part A 37(12):2226-2235. doi:10.1016/j.compositesa.2005.12.031

2. Gibson RF (2016) Principles of composite material mechanics. CRC Press, Boca Raton

3. Muthyala VD (2007) Composite sandwich structure with grid stiffened core. Master's Thesis, Osmania University, Hyderabad

4. Caprino G, Teti R (1994) Impact and post-impact behavior of foam core sandwich structures. Compos Struct 29(1):47-55. doi:10.1016/0263-8223(94)90035-3

5. Shipsha A, Zenkert D (2005) Compression-after-impact strength of sandwich panels with core crushing damage. Appl Compos Mater 12(3-4):149-164

6. McGowan DM, Ambur DR Damage characteristics and residual strength of composite sandwich panels impacted with and without compression loading. In: Proceedings of the 39th AIAA/ASME/ ASCE/AHS/ASC Structures, Structural Dynamics, and Materials Conference, 1998. pp 20-23

7. Anderson T, Madenci E (2000) Experimental investigation of low-velocity impact characteristics of sandwich composites. Compos Struct 50(3):239-247

8. Vaidya UK, Pillay S, Bartus S, Ulven CA, Grow DT, Mathew B (2006) Impact and post-impact vibration response of protective metal foam composite sandwich plates. Mater Sci Eng 428(1):59-66

9. Imielińska K, Guillaumat L, Wojtyra R, Castaings M (2008) Effects of manufacturing and face/core bonding on impact damage in glass/polyester-PVC foam core sandwich panels. Compos Part B 39(6):1034-1041

10. Ulven C, Vaidya U (2008) Impact response of fire damaged polymer-based composite materials. Compos B 39(1):92-107

11. Deka L (2008) Vaidya U LS-DYNA ${ }^{\circledR}$ Impact simulation of composite sandwich structures with balsa wood core. In 10th International LS-DYNA users Conference

12. Atas C, Sevim C (2010) On the impact response of sandwich composites with cores of balsa wood and PVC foam. Compos Struct 93(1):40-48

13. Wang B, Wu L-Z, Ma L, Feng J-C (2011) Low-velocity impact characteristics and residual tensile strength of carbon fiber composite lattice core sandwich structures. Compos Part B 42(4):891-897

14. Kim C-G, Jun E-J (1992) Impact resistance of composite laminated sandwich plates. J Compos Mater 26(15):2247-2261

15. Vlot A (1993) Low-velocity impact loading: on fibre reinforced aluminium laminates (ARALL and GLARE) and other aircraft sheet materials. Delft University of Technology, Delft

16. Zhang X, Davies G, Hitchings D (1999) Impact damage with compressive preload and post-impact compression of carbon composite plates. Int J Impact Eng 22(5):485-509

17. Dhaliwal GS, Newaz GM (2016) Modeling low velocity impact response of carbon fiber reinforced aluminum laminates (CARALL). J Dyn Behav Mater 2(2):181-193. doi:10.1007/s40870016-0057-3

18. Dhaliwal GS, Newaz GM (2016) Experimental and numerical investigation of flexural behavior of carbon fiber reinforced aluminum laminates. J Reinf Plast Compos. doi:10.1177/ 0731684416632606

19. Dhaliwal GS, Newaz GM (2016) Effect of layer structure on dynamic response and failure characteristics of carbon fiber reinforced aluminum laminates (CARALL). J Dyn Behav Mater 2(2):399-409. doi:10.1007/s40870-016-0075-1

20. Eyvazian A, Akbarzadeh I, Shakeri M (2012) Experimental study of corrugated tubes under lateral loading. Proceedings of the 
Institution of Mechanical Engineers, Part L: J Mater Des Appl:1464420712437307

21. Eyvazian A, Habibi MK, Hamouda AM, Hedayati R (2014) Axial crushing behavior and energy absorption efficiency of corrugated tubes. Mater Des 54:1028-1038

22. Strait L, Karasek M, Amateau M (1992) Effects of stacking sequence on the impact resistance of carbon fiber reinforced thermoplastic toughened epoxy laminates. J Compos Mater 26(12):1725-1740

23. Dost EF, Ilcewicz LB, Avery WB, Coxon BR (1991) Effects of stacking sequence on impact damage resistance and residual strength for quasi-isotropic laminates. In: Composite materials: fatigue and fracture, vol 3. ASTM International, Pennsylvania

24. Caprino G, Lopresto V, Scarponi C, Briotti G (1999) Influence of material thickness on the response of carbon-fabric/epoxy panels to low velocity impact. Compos Sci Technol 59(15):2279-2286

25. Luo R, Green E, Morrison C (2001) An approach to evaluate the impact damage initiation and propagation in composite plates. Compos Part B 32(6):513-520
26. Sadasivam B, Mallick P (2002) Impact damage resistance of random fiber reinforced automotive composites. J Thermoplast Compos Mater 15(3):181-191

27. Cho C, Zhao G (2002) Effects of geometric and material factors on mechanical response of laminated composites due to low velocity impact. J Compos Mater 36(12):1403-1428

28. Phadatare AS (2012) Flexural analysis of balsa core sandwich composite: failure mechanisms, core grain orientation and padding effect. Wayne State University, Detroit

29. Manual L-DKUs (2007) Livermore Software Technology Corporation (LSTC). California, USA

30. Vaidya UK, Deka LJ (2009) Single and multisite impact response of S2-glass/epoxy balsa wood core sandwich composites. In: Major accomplishments in composite materials and sandwich structures. Springer, Berlin, pp 541-569

31. Hallquist JO (2006) LS-DYNA theory manual. Livermore Softw Technol Corp 3:25-31 